\title{
Letter to Editor:
}

\section{COVID-19 Impact on the Rehabilitation of People With Disabilities Using Prosthetic and Orthotic Devices}

\author{
Akshay $\operatorname{Kumar}^{1}$ (D, Vinita $^{2}$ (D)
}

1. Department of Prosthetics \& Orthotics, Composite Regional Centre for Skill Development, Rehabilitation, and Empowerment of Persons With Disabilities, Kozhikode, Kerala, India.

2. Pace Rehabilitation, Research, and Artificial Limb Centre, Kozhikode, Kerala

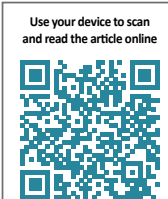

Crte this artice as Kumar A, Vinita. COVID-19 Impact on the Rehabilitation of People With Disabilities Using Prosthetic and Orthotic Devices. Function and Disability Journal. 2021; 4:E1. http://dx.doi.org/10.32598/fdj.4.171.1

http://dx.doi.org/10.32598/fdj.4.171.1

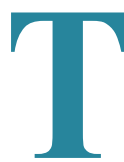

he novel Coronavirus Disease-19 (COVID-19) posed a high global public health threat. Implementing preventive and control measures, the whole world made effort to prevent the spread of the deadly virus [1]. The spread of the disease was higher in densely populated regions, especially in middle and lowincome countries, as the measures of social distancing were difficult to implement and rehabilitation facilities are inadequate and inefficient in many such countries [2]. The COVID-19 pandemic impacted our daily life activities, movements, and business and led to profound consequences for public healthcare, economy, and sociopsychological elements [3]. Compared with the general population, people with disabilities need better health care facilities within their reach for their well-being [4].

According to the report published by the World Health Organisation and World Bank in 2011, about 15\% of the world population were estimated to be live with some forms of disability, also, $2 \%$ to $4 \%$ of the population experienced severe functioning difficulties, needing immediate assistive technology interventions [5].
The COVID-19 pandemic is likely to push people with locomotor disabilities at a high risk of morbidity and mortality, compared with other populations. The main reason for this seems to be a disparity in access to public health facilities. Physical distancing and self-isolation further disrupted the services to the people with locomotor disabilities, who depended on caregivers for personal care and daily living activities [6]. Due to the existing comorbidities, they might be prone to health issues and respiratory syndrome [7]. Also, the difficulties in day-today activities and support system might result in their behavioral changes and returning to routine work [8].

However, the state-imposed lockdown during the pandemic not only affected economic and social interaction [9] but also led to many challenges for prosthetic and orthotic users in low and middle-income countries. The demand for prosthetic and orthotic services is increasing daily in developing countries [10]. There are about 40 million amputees in developing countries, and only 5\% of them have access to prosthetic care as reported by the World Health Organization. The professionals' strength is lacking for proper service delivery. The standard need for prosthetics and orthotics delivery is 5 to 10 orthotics

* Corresponding Author:

Akshay Kumar

Address: Department of Prosthetics \& Orthotics, Composite Regional Centre for Skill Development, Rehabilitation, and Empowerment of Persons With Disabilities, Kozhikode, Kerala, India.

Tel: +91 (84) 34164590

E-mail:akshaypoist@gmail.com 
and prosthetics clinicians per million population. However, for middle and low-income countries like India, the corresponding figure is just one $[11,12]$.

Transportation, mobility needs, societal attitudinal barriers, and environmental access issues have also been identified as a global challenge for people with disabilities [13]. During the pandemic, the government norms either ignored the interest of the people with disabilities or adversely affected the whole system, deteriorating their quality of life [14]. Furthermore, the majority of the government institutions and service modalities are providing only online teleservices (by video and on phone calls), which are becoming a new normal to both the service users and providers. But satisfaction and accuracy in prosthetic and orthotic rehabilitation are yet to be established, as prosthetic and orthotic rehabilitation need more physical contact for better outcome [15]

During the pandemic, telehealth emerged as a potential healthcare delivery system to provide treatment for those living in remote areas with no access to rehabilitation services. It also provides a cost-effective option to the clinicians and the clients. However, clinical satisfaction and effectiveness are yet to be properly assessed [16]. The advantages of telerehabilitation include a reduction in travel time and low cost for patients and caregivers. It promotes multidisciplinary teamwork and easy monitoring in remote areas. However, the liability concern of professionals increases in the case of teleconsultation. Major concerns in this area include the lack of broadband facilities in many locations especially in middle and low-income states and the issue of security to the patients' privacy [17].

Presently telehealth rehabilitation utility, though limited, is encouraging. Further research is needed to find out which prosthetic and orthotic assessments and treatments are feasible through the telehealth service delivery. However, the interventions that need physical contact with the patients may not be effective and efficient enough when delivered through telehealth modalities [18]. The application of the advanced technology of artificial intelligence may help to attain the goal of prosthetic and orthotic rehabilitation with minimal human intervention [19].

The application of the advanced technology of artificial intelligence may help to attain the goal of prosthetic and orthotic rehabilitation with minimal human intervention. Currently, the technology is being used for the advanced care of neuropsychiatries, myoelectric control, gait training, patient data measurement, clinical decision, etc.
Nevertheless, existing technologies are yet to evolve and become user-friendly to deliver greater good to the patients, rehabilitation professionals, and caregivers [20].

Technology up-gradation needs to continue enhancing future rehabilitation service delivery. Also, the governments, NGOs, and prosthetic and orthotic industries have to keep on generating the required infrastructure to favor digital transformation post-COVID-19.

\section{Ethical Considerations}

Funding

This research did not receive any grant from funding agencies in the public, commercial, or non-profit sectors.

\section{Authors' contributions}

Both authors equally contributed to preparing this article.

Conflict of interest

The authors declared no conflict of interest.

\section{References}

[1] Dhama K, Khan S, Tiwari R, Sircar S, Bhat S, Malik YS, et al. Coronavirus disease 2019-COVID-19. Clin Microbiol Rev. 2020; 33(4):e00028-20. [DOI:10.1128/CMR.00028-20] [PMID] [PMCID]

[2] Amatya B, Khan F. Rehabilitation response in pandemics. Am J Phys Med Rehabil. 2020; 99(8):663-8. [DOI:10.1097/ PHM.0000000000001477] [PMID] [PMCID]

[3] Haleem A, Javaid M, Vaishya R. Effects of COVID-19 pandemic in daily life. Curr Med Res Pract. 2020; 10(2):78-9. [DOI:10.1016/j. cmrp.2020.03.011] [PMID] [PMCID]

[4] United Nations. COVID-19 outbreak and persons with disabilities [Internet]. 2020 [Updated 2020 July 24]. Available from: https:/ www.un.org/development/desa/disabilities/covid-19.html

[5] World Health Organization. World report on disability [Internet]. 2011 [Updated 2011]. Available from: https://www.who.int/disabilities/world_report/2011/report.pdf

[6] Lebrasseur A, Fortin-Bédard N, Lettre J, Bussières EL, Best K, Boucher N, et al. Impact of COVID-19 on people with physical disabilities: A rapid review. Disabil Health J. 2021; 14(1):101014. [DOI:10.1016/j.dhjo.2020.101014] [PMID] [PMCID]

[7] Armitage R, Nellums LB. The COVID-19 response must be disability inclusive. Lancet Public Health. 2020; 5(5):e257. [DOI:10.1016/ S2468-2667(20)30076-1] 
[8] Turk MA, McDermott S. The COVID-19 pandemic and people with disability. Disabil Health J. 2020; 13(3):100944. [DOI:10.1016/j. dhjo.2020.100944] [PMID] [PMCID]

[9] Ozili P. COVID-19 in Africa: Socio-economic impact, policy response and opportunities. Int J Sociol Soc Policy. 2020. [DOI:10.1108/IJSSP-05-2020-0171]

[10] Harkins CS, McGarryA, BuisA.Provision of prosthetic and orthotic services in low-income countries: A review of the literature. Prosthet Orthot Int. 2013; 37(5):353-61. [DOI:10.1177/0309364612470963] [PMID]

[11] Kumar A, Vinita. Prosthetics and orthotics in rehabilitation: A short communication. Glob J Res Anal. 2020; 9(8):17-8. [DOI:10.36106/ gjra/5305581]

[12] Kumar A, Vinita . Current status of prosthetic and orthotic rehabilitation services in India: Its issues and challenges. Front Health Inform. 2021; 10:55. [DOI:10.30699/fhi.v10i1.258]

[13] Kett M, Cole E, Turner J. Disability, mobility and transport in low- and middle-Income countries: A thematic review. Sustainability. 2020; 12(2):589. [DOI:10.3390/su12020589]

[14] Thelwall M, Levitt JM. Retweeting COVID-19 disability issues: Risks, support and outrage. El profesional de la Información. 2020; 29(2):e290216. [DOI:10.3145/epi.2020.mar.16]

[15] Binedell T, Subburaj K, Wong Y, Blessing LTM. Leveraging digital technology to overcome barriers in the prosthetic and orthotic industry: Evaluation of its applicability and use during the COVID-19 pandemic. JMIR Rehabil Assist Technol. 2020; 7(2):e23827. [PMID] [PMCID] [DOI:10.3145/epi.2020.mar.16]

[16] Jacobs K, Blanchard B, Baker N. Telehealth and ergonomics: A pilot study. Technol Heal Care. 2012; 20(5):445-58. [DOI:10.3233/ THC-2012-0692] [PMID]

[17] Fairly M. Across the state or around the world: Telerehabilitation technologies Cover the distance [Internet]. 2016 [Updated 2016 May]. Available from: https://opedge.com/Articles/ViewArticle/2016-04-25/2016-05_01

[18] Cason J. Telehealth: A rapidly developing service delivery model for occupational therapy. Int J Telerehabil. 2014; 6(1):29-35. [DOI:10.5195/ijt.2014.6148] [PMID] [PMCID]

[19] Fazekas G, Tavaszi I. The future role of robots in neuro-rehabilitation. Expert Rev Neurother. 2019; 19(6):471-3. [DOI:10.1080/1473 7175.2019.1617700] [PMID]

[20] Luxton DD, Riek LD. Artificial intelligence and robotics in rehabilitation. In: Brenner LA, Reid-Arndt SA, Elliott TR, Frank RG, Caplan B, editors. Handbook of rehabilitation psychology. Washington, D.C: American Psychological Association; 2019. [DOI:10.1037/0000129-031] 
This Page Intentionally Left Blank 